\title{
Research on the Design of Internal Public Space in Residential Buildings in the Post-pandemic Era
}

\author{
Xinyue $\mathrm{Liao}^{1}$ Kai Cao ${ }^{1, *}$ \\ ${ }^{1}$ College of Art and Design, Wuhan Textile University, Wuhan, Hubei 430073, China \\ *Corresponding author. Email: Caokai78@vip.qq.com
}

\begin{abstract}
This article starts with the status quo of public spaces inside residential buildings, puts forward people's new requirements for residential public space design in the post-pandemic era, analyzes and summarizes corresponding design strategies, and applies them to public spaces in residential buildings in the post-pandemic era, to create a green and healthy community construction and harmonious neighborhood communication, thereby satisfying people's material and spiritual needs for residential public spaces.
\end{abstract}

Keywords: Post-pandemic era, Public space design, Residential interior, Being green and healthy.

\section{INTRODUCTION}

Public space design cannot be carried out in isolation from the social reality. Against different social backgrounds, people have different needs for public space design. The public space in modern residences is also a space that architects and interior designers are keen to explore and innovate, in order to pursue a harmonious atmosphere of communication among residents in the modern living environment.

At the end of 2019, after the sudden emergence of the COVID-19 pandemic, people need to stay at home for a long time, and the existing public space design in residential buildings not only cannot meet the needs of people in quarantine for interpersonal communication, but also cannot give priority to preventing the pandemic and being safe. In this way, it is necessary to seriously consider from a development perspective. In the post-pandemic era, the internal public space of the house should create a physiologically comfortable livable environment and a psychologically comfortable humanistic environment, so as to achieve a win-win situation.

\section{THE IMPACT OF THE PANDEMIC ON THE PUBLIC SPACE OF URBAN HOUSING CONSTRUCTION}

With the continuous development of the modernization of Chinese cities and towns, people's living standards have also improved significantly. People pay more and more attention to the quality of the living environment, and pay more and more attention to the construction of public space in residential areas. [1] While urban housing construction is maintaining rapid development, people have to recognize the impact of public health incidents such as the outbreak of the COVID-19 pandemic on urban housing construction. The sudden outbreak of the COVID19 pandemic at the end of 2019 has a major impact on residential construction design practitioners in China. As far as the public space in residential areas is concerned, most of the public spaces in residential areas have to be banned or even prohibited from being used by residents during the pandemic. It makes people live in the house for a long time and lacks interpersonal communication.

Although the Chinese epidemic is well under control at this stage, the end of the global pandemic is still unclear, and it is not very optimistic to control the pandemic completely. [2] Therefore, how to design public spaces in residential areas to 
respond to the current epidemic period with a "new attitude", so that people can socialize safely is more important. There are many problems that need to be resolved, especially the pandemic has caused people's long-term psychological changes in their homes, and the needs of green, health, and safety have put forward higher demands for their development.

In order to cope with this series of problems, the hall space, corridor space, stairwell, roof activity space, etc., as important components and key nodes of the public space inside residential buildings, need to be combined with the background of the post-pandemic era to satisfy people and carry out creative thinking, thus building a green and healthy space environment from the interaction and influence of behavior patterns, psychological needs, and space environment. From its internal point of view, against the background of the inseparable era of public space design and public health, the design of public space inside residential buildings is designed and considered and the development concept of "healthy city" is implemented.

\section{NEW NEEDS FOR THE DESIGN OF INTERNAL PUBLIC SPACES IN RESIDENTIAL BUILDINGS IN THE POST-PANDEMIC ERA}

With the continuous economic development, unparalleled changes have taken place in urban construction and human settlements, and people's living standards have also been significantly improved. People are paying more and more attention to the quality of the living environment. In addition to paying more and more attention to housing types, residents are also paying more and more attention to public spaces in residential areas. [3] In the current residential planning, designers pay more attention to the design of outdoor public spaces, while paying little attention to the interior. However, in order to establish a harmonious neighborhood relationship, both must be considered at the same time to make it an organic whole.

In the post-pandemic era after the COVID-19 outbreak, it is necessary to analyze in detail the psychological changes and behavioral changes of "people" in residential buildings due to the impact of the pandemic, use this as a basis to consider and explore the design of internal public space in residential buildings, and finally solve the new needs of internal public space design in residential buildings in the post-pandemic era.

\subsection{The Psychological Problems of "People" in the Post-pandemic Era Require an Open Space for Circulation}

The major outbreak of the COVID-19 pandemic has become the largest global public health security incident facing humanity after entering the 21st century. Due to the extreme spread of the pandemic, the extremely diverse transmission methods, the huge difficulty of prevention and control, and the end time of the pandemic, it is difficult to estimate a series of current situations. Therefore, every ordinary citizen can feel the huge threat posed by the pandemic, and have developed negative emotions of fear to varying degrees. Coupled with prolonged isolation at home and unable to go out, negative emotions of anxiety have gradually appeared. Therefore, "people" will inevitably have new demands for the spatial form of public space.

Residential buildings in urban residential areas have the characteristics of transportation architecture for the flow of people, and the spatial forms of their internal public spaces are basically closed. This would have brought more suppressed negative emotions to the residents, and in the long run it would cause physical discomfort. This shows that the physical space of the building and the psychological emotions of people are bound to interact and influence.

When negative emotions suddenly increase due to the pandemic and the long-term spatial environment, the external performance of "people" will also change negatively, causing "people" to have new demands for the space environment. From an essential point of view, "people" will have a great increase in demand for open space forms, including the scale, measurement, and illuminance of the public space in the residence.

\subsection{In the Post-pandemic Era, the Negative Automatic Thinking of "People" Requires a Humanized Spatial Form}

Negative automatic thinking means that individuals will have negative emotions to attribute to the cause and effect of anything. Therefore, the pandemic has brought severe challenges to the public's psychology. During the pandemic, a large number of false rumors spread wildly on the Internet, causing the public to panic, causing their negative automatic thinking to perform cognitive processing of these false messages, such as excessive attention to their own physical conditions, being hostile to the "behaviors" of others and 
appearing "infected" psychological projections. Due to the interaction and influence between people's psychological emotions and the physical space of the building, when staying at home for a long time and not communicating with people, the subjective perception and behavioral experience of "people" will fall into negative and passive understandings. In addition, residential buildings are spaces for long-term relationships with "people" during the pandemic, so they are worthy of the designers' attention.

From the perspective of humanized design, the design of public space inside residential buildings needs to pay attention to the psychological emotions of residents, make them psychologically happy, and let residents experience the safety and comfort of the public space from the foyer space, corridor space, stairwell, roof activity space, etc. inside the residential building.

\subsection{In the Post-pandemic Era, Avoidance Behavior of "People" Requires a Reasonable and Orderly Spatial Form}

Due to the strong spread of COVID-19, the diverse transmission routes, and the unclear incubation period, the sense of distance between people has increased. Therefore, in the design of public spaces, it is necessary to consider how to avoid direct contact between people.

Since the traffic function is an indispensable function of the public space inside a residential building, the avoidance behavior of residents will be more obvious when facing the necessary traffic travel, and the demand for a reasonable and orderly space form will be very urgent. The avoidance behavior is directly related to social fear in psychology. The generation of social fear is not all congenital, and acquired lack of interpersonal communication can also cause the fears. Therefore, the design of the internal public space of residential buildings is not to isolate the communication between people, but to allow people to socialize safely through a reasonable and orderly space form, and eliminate the avoidance behavior of "people" due to negative emotions.

\subsection{Flexible Space for Sustainable Application in Response to Major Emergencies in the Post-pandemic Era}

Flexible space, as the name implies, makes the space shrink and extend freely and full of flexibility. The design of the internal public space of residential buildings needs to be people-oriented, pay attention to the feedback of residents' use experience, and flexibly adjust the space form to meet the ever-changing needs of residents in use.

When the public space in the residential area is facing an emergency such as the COVID-19 pandemic, the design of its flexible space is very inadequate. The internal public spaces of traditional residential buildings, such as lobby space, corridor space, stairwell, and roof activity space, are often limited to only bear a certain aspect of functional requirements, and cannot flexibly adjust their spatial forms according to different residents' needs.

Therefore, it is necessary to not only take the COVID-19 pandemic as the starting point to think and explore the design requirements and forms of the public space inside the residence, but also meet and respond to the users' demand on current environment when disasters such as earthquakes, floods, and typhoons come. It can be said that paying attention to the elastic space properties in the internal public spaces of residential buildings is a kind of foresight research to prevent problems before they happen. [4]

Based on the above discussion, designers should realize the importance of public space design in residential buildings to people. The development of the times and the emergence of emergencies have put forward new requirements for public space. The design and use of public space will provide new ideas for community construction.

\section{THE DESIGN STRATEGY OF THE INTERNAL PUBLIC SPACE OF RESIDENTIAL BUILDINGS IN THE POST-PANDEMIC ERA}

The new requirements for the design of internal public space in residential buildings in the postpandemic era mainly reveal the mismatch and inadaptability of the internal public space form of the residence under the current design form and the new requirements of residents. After clarifying these symptoms, what the designers need to continue to study is how to improve the psychological problems, behavior patterns, behavior patterns, etc. of "people" caused by the pandemic in terms of spatial environment, spatial order, and spatial form, and to find out the proper design strategy. 


\subsection{Design Strategies for the Spatial Environment that Adapt to the Physical and Psychological Needs of "People" Under the Pandemic}

The first is that in the design of the entrance hall, in order to present a space form that makes residents happy, greater efforts should be made to add the use of gray space to allow a more complete outdoor space to be embedded in the interior. The penetration of the external landscape and the organic integration of the indoor space allow more courtyards and sunlight to penetrate into the space of the foyer, making people happy to stay here and feel safe. The second is to pay attention to the spatial scale that residents feel safe in traffic spaces such as corridor spaces. At this stage, the corridor space inside residential buildings lacks the "sharing" of the place, which prevents people from intersecting. Architectural designers can appropriately expand the space scale of the corridor space to form a sky courtyard, making it the second living room of the residential area, thus creating the possibility for the occurrence of communication. The third is to increase safety and health design measures. In current residential buildings, elevators, as the main vertical transportation, carry people's travel. Buttons for sensing gestures, disinfection facilities, and ventilation ducts should all be added to it. For stairwells that are seldom used, the platform space should also be expanded, daylighting and air circulation should be increased, so that the platform space can be claimed and used by residents, creating their own "courtyard", forming a vertical green traffic channel, and enhancing the use of stairwells, so as to enhance people's sense of happiness and participation in life during the pandemic. The forth is the reasonable use of roof activity space, highlighting humanized care. Currently, the roof activity space of residential buildings is mainly used for drying clothes and planting plants. Since the phototaxis of "people" is more apparent during the pandemic, a reasonable gathering area is created in the roof activity space, which is also helpful for firefighting and evacuation. The fifth is that natural ventilation, enhanced lighting, and planting of green plants should be considered in the spatial forms of public spaces inside different residences to meet the physiological needs of "people".

\subsection{Design Strategies to Create a Reasonable and Orderly Space Form}

The efficient and reasonable spatial order of the internal public space of residential buildings basically starts from the various behaviors and activities of each resident when using the public space, and adopts reasonable design strategies to provide scientific collection and distribution, diversion, staying time, etc., so that residents can use each public space efficiently, safely and comfortably. [5]

A reasonable design strategy not only requires the cooperation of architects and interior designers, interaction designers and software engineers can also provide tremendous help. When residents want to use a certain public space, they can make an appointment through the developed app to determine the time, place, and number of users. This kind of operation is very common in modern society. Even the elderly who are not familiar with the use of smart phones can make corresponding appointments through the phone calls. [6]

Of course, the designers must also pay attention to reasonable and efficient streamline settings, so as to save residents' time on the road. For example, they can set up single-deck stays or high-low stays for elevators, set up staggered stairs to form a rich flow line, which the flow line is as short and effective as possible, and access to various public spaces can be unimpeded.

\subsection{Design Strategies for Creating Sustainable Flexible Spaces}

The first is to make it clear that the design of public spaces inside residential buildings can not only meet the current functional requirements, but also retain some sustainable flexible spaces. It is a must to consider and prepare the layout from the normalized and abnormal functions, and explore a variety of spatial forms. The second is that it is not only necessary to consider the impact of the epidemic on the spatial form design, but also to prepare for various other natural and man-made disasters. Eventually, the internal public space of residential buildings has evolved into a spatial form capable of adapting to different situations and tenses.

\section{CONCLUSION}

The sudden outbreak and rapid development of the COVID-19 epidemic has aroused people's 
attention and research, but most of the current research is reflected in the field of medicine, and there are not many discussions on the combination of pandemic and design. In addition, there are very few researches focusing on the design of the internal public space of residential buildings and the post-pandemic background. China has the largest population in the world. The public space inside the residence is an important part. It deserves more attention. It is particularly necessary to combine the specific background of the pandemic to meet the new needs of residents for design innovation.

The design of public spaces in residential buildings requires not only the design of professional designers, but also the participation of residents, so as to fundamentally solve the new needs of residents for safety, health, greenness and comfort under the pandemic prevention and control, and finally realize residents' dual satisfaction at the physical and psychological levels.

\section{AUTHORS' CONTRIBUTIONS}

Xinyue Liao is responsible for wrote the manuscript. Kai Cao contributed to revising and editing.

\section{REFERENCES}

[1] Chen Cheng, Research on Public Space in Urban Residential Building Design [D]. Shanghai Normal University, 2018. (in Chinese)

[2] Xiao Wei, Song Yi, The Rapid Response to Emergencies: Thoughts on "Anti-Epidemic Design" During the Outbreak of COVID-19 [J]. Architectural Journal, 2020, (Z1). (in Chinese)

[3] Liu Lingfang, Analysis of Public Space Design in Residential Building Design [J]. Construction Materials \& Decoration, 2020(13): 96, 100. (in Chinese)

[4] Yu Guoming, Regain Trust: The Difficulty, Construction and Key of Communication Governance in Post-epidemic Era [J]. Journalism and Mass Communication Monthly, 2020, (5). (in Chinese)

[5] Chen Cheng, Research on Public Space in Urban Residential Building Design [D]. Shanghai Normal University, 2018. (in Chinese)
[6] Wu Dexing, Design of urban public facilities from the perspective of humanization [J]. Packaging Engineering, 2019, (6). (in Chinese) 